\title{
Photochemistry of Anthrylethene Derivatives Containing Heteroaromatic Ring : Pyrrole and Indole Derivatives
}

\author{
Eun Ju Shin \\ Deparment of Chemistm, Sunchon National Universitw, Sunchon, Chomnam 540-7+2. Korea \\ Received Februarv 25, 2004
}

Key Words : Diarylethene. Pyrrole. Indole, Fluorescence. Intramolecular charge transfer

Diarylethenes are generally known to perform reversible photochemical cis-t $/ m s$ isomerization. However. 1-(9anthrỵl)-2-phenylethene(9-APE) executes efficient cis $\rightarrow$ trans photoisomerization but do not undergo reverse $t / m s \rightarrow$ cis photoisomerization. ${ }^{1-6}$ The excitation energy is extensively localized in the large anthracene moiety so that the transoid geometry corresponds to energy minima in the excited potential energy surface. The energy barrier to $\mathrm{C}=\mathrm{C}$ bond twisting is too high for $t-9-\mathrm{APE}$ to undergo $t r a m s \rightarrow c$ is photoisomerization.

Intramolecular charge transfer (ICT) could provide a way to lower the activation barrier to twisting of ethene bond in anthrylethene derivatives. Introduction of heteroaromatic ring into anthrylethene increases the dipole moment of the compound to initiate the excited state ICT processes.

Nitrogen-heteroaromatic derivatives of 9-APE containing pyridine. ${ }^{8 . \overline{ }}$ pyrazine. ${ }^{10}$ or quinoline ring ${ }^{1 l .12}$ in place of phenyl ring perform trans $\rightarrow$ cis photoisomerization as well as cis $\rightarrow$ trons photoisomerization. depending on the medium. In comparison with parent 9-APE. the aza substitution changes the donor-acceptor properties of the molecules. ${ }^{8-1}=$ Pyyridine is referred to as an electron-deficient heterocycle and has some analogy with a benzene ring that carries an electron-withdrawing substituent. As pyridine. pyrazine. or quinoline ring acts as an electron acceptor. intramolecular charge transfer processes should affect on the excited state properties of nitrogen-heteroaromatic derivatives of 9-APE. As reported in our previous papers. 1-(9-antluy 1)2-(n-pyrridyl)ethenes (n-APyE, $n=2$ or 4$)^{8}$ and 1 -(9-anthry l)2-(n-quinolyl)ethenes(n-AQE $n=2$ or 4 ) ${ }^{1=}$ mono-aza analogues of 9-APE. show efficient $t / m \rightarrow s \rightarrow$ cis photoisomerization in polar solvent. and 1-(9-anthryl)-2-pyrazinylethene( $\mathrm{APzE}){ }^{10}$ a di-aza analogue of 9-APE, exhibits trans Ecis photoisomerization even in nonpolar solvent.

On the other hand. pyrrole is referred to as an electron-rich heterocycle and has some analogy with a benzene ring that carries an electron-donating substituent. In this paper. we prepared 9-APE derivatives containing electron-rich pyrrole or indole ring and insestigated their excited-state properties in comparison with electron-deficient pyridine derivative 4APỵ.E.
Absorption and fluorescence spectra of t-2-APyrE, $t$-2$\mathrm{AIE}$, and $t-2-\mathrm{AMIE}$ in cyclohexane and acetonitrile are shown in Figure 1. Table 1 summarizes absorption and fluorescence data of $t$-2-APyrE, $t$-2-AIE, and $t$-2-AMIE along with those of t-9-APE and $t-4-\mathrm{APy}$. Absorption spectral shape and its maxima are not nearly influenced by the solvent polarity for all the compounds studied.

In contrast to the absorption spectra. fluorescence maxima and quantum yields are strongly dependent on the solvent polarity as well as the kind of the heteroaromatic ring introduced into 9-APE. For a hydrocarbon $t-9-\mathrm{APE}$. the fluorescence wavelength maxima and fluorescence quantum yields remain unchanged in the solvents of different polarity. However, a pyridine derivative $t-4-\mathrm{APyE}$ (see Table 1) shows large red-shift of the fluorescence maximum and remarkable decrease of fluorescence quantum yield in polar solvents. As for the fluorescence of indole derivative $t-2-\mathrm{AIE}$, unusually large solvatochromic effect is observed. The fluorescence spectrum of $t$-2-AIE is much more red-shifted $(62 \mathrm{~nm})$ in polar solvents relative to that of $t-4-\mathrm{APy} E(26 \mathrm{~nm})$. and their fluorescence quantum yields are greatly reduced in polar solvents (Figure 1 and Table 1). Fluorescence quantum yield of pyrrole derivative $t-2-A P y r E$ is much more reduced in polar solvent than that of indole derivative $t$-2-AIE. In fact. $t$ 2-APyrrE shows no fluorescence in acetonitrile. These solvatocluromic effects on the fluorescence spectra are probably due to the stabilization of the excited intramolecular charge transfer (ICT) state in polar solvents. $t$-2-AMIE is less dependent on the solvent polarity than $t$-2-AIE for both fluorescence wavelength and quantum yield and. even in cyclohexane. red-shifted fluorescence spectra are observed in much longer wavelength than that of $1-9$-APE.

All the compounds studied executed no photoisomerization in cyclohexane (see Table 1). In acetonitrile photoisomerization reactions of pyrrole and indole heteroaromatic derivatives t-2-APyrE and t-2-AIE upon irradiation are relatively efficient like $1-4-\mathrm{APyE}$. Photoisomerization quantum yield of $t-2$-AMIE in acetonitrile is smaller than those of $t-2$ APyre and $t$-2-AIE. For $t-2-\mathrm{AP} y \mathrm{rE}, t-2-\mathrm{AIE}$, and $t$-2-AMIE, the decrease of the fluorescence quantum yields in polar solvents are compensated with the increase of the photo- 


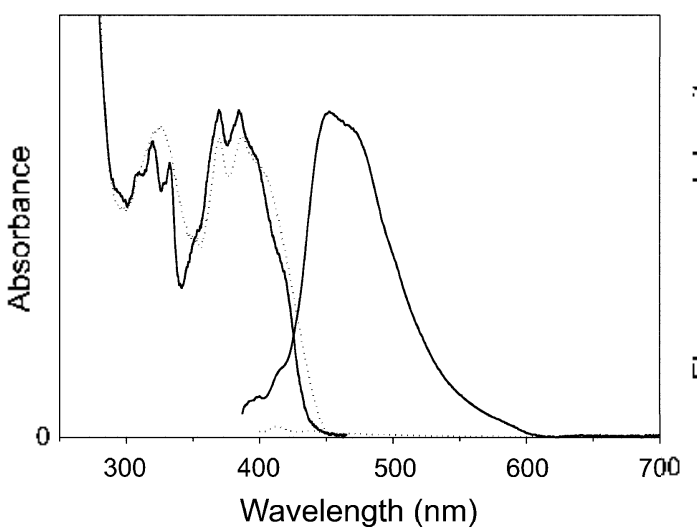

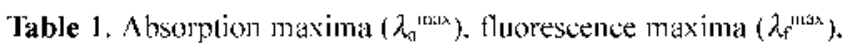
and quantum yiclds $\left(\Phi_{f}\right)$ of of $t-9-\Lambda$ PE. $t-4-\Lambda$ PyL. $t-2-\Lambda$ PyrE. $t-2-$ AIE. and $t$-2-AMIE in cyclohexane and acetonitrile

\begin{tabular}{|c|c|c|c|c|c|}
\hline compound & solven & $\lambda_{\mathrm{a}}^{\max } \mathrm{nmm}$ & $\lambda_{i}^{t a n a x} / n m$ & $\Phi_{f}$ & $\Phi_{t \rightarrow c}$ \\
\hline \multirow{2}{*}{$t-9-\mathrm{Al}^{3} \mathrm{r}^{a t}$} & cyclohexane & 385 & 468 & 0.44 & $<0.01$ \\
\hline & actonitrile & 385 & 476 & 0.45 & 0.003 \\
\hline \multirow{2}{*}{$t-4-A P y l^{t^{h}}$} & cyclohexane & 386 & 473 & 0.44 & $<0.01$ \\
\hline & acctonitrile & 388 & 499 & 0.04 & 0.37 \\
\hline \multirow{2}{*}{$t-2-\mathrm{AP} \mathrm{rE}$} & cyclohexane & 385 & 471 & 0.42 & $<0.01$ \\
\hline & acelonitrile & 387 & not delected & $\cdots$ & 0.28 \\
\hline \multirow{2}{*}{$t-2$-AIr: } & cyclohexane & 371 & 471 & 0.32 & $<0.01$ \\
\hline & acetonitrile & 370 & 533 & 0.02 & 0.20 \\
\hline \multirow{2}{*}{$t-2-$ AMII: } & cyclohexane & 389 & 540 & 0.34 & $<0.01$ \\
\hline & acctonitrile & 387 & 558 & 0.13 & 0.07 \\
\hline
\end{tabular}

"Data from ref. 13. "])ata from ref. 9.

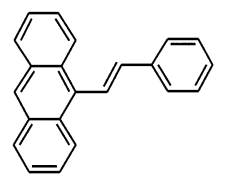

t-9-APE

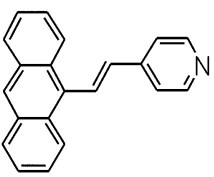

t-4-APyE

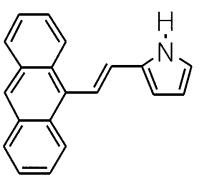

t-2-APyrE

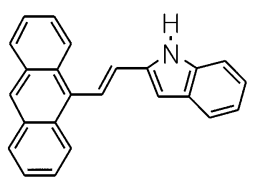

t-2-AIE

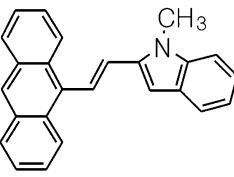

t-2-AMIE

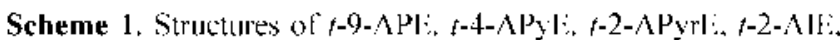
and $t-2-A \mathrm{MIL}$.

\section{Experimental Section}

Syntheses of 2-APyrE, 2-AIE, and 2-AMIE were accomplished by Wittig reactions between 9-anthrylmethyltriphenylphosphonium bromide and corresponding aldehydes. using similar method as reported previously. ${ }^{13}$ Their structures were identified by 'H-NMR and mass spectra.

t-2-APy $\%$ : yellow solid; 'H NMR ( $\left.300 \mathrm{MHz}, \mathrm{CDCl}_{3}\right) \delta$ 6.45-6.53 (2H, m, pyrrole $\mathrm{H3}, 4), 6.91-6.95$ ( $1 \mathrm{H}, \mathrm{m}$, pyrrole $\mathrm{H} 5), 7.34-7.52(6 \mathrm{H}, \mathrm{m}$, anthracene $\mathrm{H} 2,3,6,7$, central double bond $\mathrm{CH}), 7.80(\mathrm{lH}, \mathrm{s}, \mathrm{NH}), 7.98-8.06(4 \mathrm{H}, \mathrm{m}$, anthracene $\mathrm{H} 4,5), 8.41-8.46(3 \mathrm{H}, \mathrm{m}$, anthracene $\mathrm{HI}, 8,10)$. MS m/e $269\left(\mathrm{M}^{\prime}\right)$.

t-2-AlE: yellow solid: 'H-NMR (CDCl $) \delta 7.00-7.10(2 \mathrm{H}$. $\mathrm{m}$, central double bond $\mathrm{CH}), 7.25-7.40(3 \mathrm{H}, \mathrm{m}$, indole $\mathrm{H3}, 5$. 6), 7.48-7.50 (4H, m, anthracene $\mathrm{H} 2,3,6,7), 7.62(\mathrm{lH}, \mathrm{d} . J$ $=8 \mathrm{~Hz}$, indole $\mathrm{H} 7), 8.01-8.07(2 \mathrm{H}, \mathrm{m}$, anthracene $\mathrm{H} 4,5)$, $8.10(1 \mathrm{H}, \mathrm{d}, J=9 \mathrm{~Hz}$, indole $\mathrm{H} 4), 8.37-8.40(2 \mathrm{H}, \mathrm{m}$. anthracene $\mathrm{HI}, 8), 8.45$ ( $1 \mathrm{H}, \mathrm{s}$, anthracene $\mathrm{HIO}$ ). MS m/e $329\left(\mathrm{M}^{\prime}\right)$.

t-2-AMIE: yellow solid; ' $\mathrm{H}-\mathrm{NMR}\left(\mathrm{CDCl}_{3}\right) \delta 3.82(3 \mathrm{H}, \mathrm{s}$, $\left.\mathrm{N}-\mathrm{CH}_{3}\right), 6.99-7.09(2 \mathrm{H}, \mathrm{m}$, central double bond $\mathrm{CH})$. 7.29$7.45(3 \mathrm{H}, \mathrm{m}$, indole $\mathrm{H} 3,5,6), 7.48-7.51(4 \mathrm{H}, \mathrm{m}$, anthracene 
$\mathrm{H} 2,3,6,7) .7 .68$ (lH. d. $J=7.8 \mathrm{~Hz}$. indole $\mathrm{H} 7) .8 .00-8.05$ $(2 \mathrm{H}, \mathrm{m}$, anthracene $\mathrm{H} 4,5), 8.20(1 \mathrm{H}, \mathrm{d}, J=9 \mathrm{~Hz}$, indole $\mathrm{H} 4)$. 8.38-8.43 $(2 \mathrm{H}, \mathrm{m}$. anthracene $\mathrm{Hl}, 8), 8.47$ (lH. s. anthracene H10). MS n/e $343\left(\mathrm{M}^{+}\right)$.

Acknow ledgment. The author would like to thank KBSI for their help in the measurement of NMR and mass spectra. This work was supported by a grant No. R04-2002-000. 00014-0 (2003) from Korea Science \& Engineering Foundation.

\section{References}

1. Arai. T: Tokumaru. K. Chem. Rev 1993.93.23.

2. Arai, T.: Tokumaru, K. Adt: Photochen. 1995, 20, 1.

3. Bartocei. G:; Masetti. F.: Mazzucato, U.: Spalletti, A.: Orlandi.
G.; Poggi, G. J. Chem. Soc. Faraday Trans. $21988,84,385$.

4. Bartocei. G.: Mazzucato. U.: Spalletti. A.: Orlandi. G.: Poggi. G. J. Chem. Soc. Foradav Trans. 1992. 88.3139.

5. Bhattacharyya. K.: Chattopadhyay. S. K.: Baral-Tosh. S.: Das. P K. J. Phis Chent 1986, 90.2646.

6. Mazzucato. U.; Spalletti. A.: Bartocei, G. Coord Chem Rev 1993. $125,251$.

7. Wang. S.-L.: Ho. T.-I. J. Photochem. Photobiol A 20M0. 135. 119

8. Shin. E. I.: Bae. E. Y.: Kiml. S. H.: Kang. H. K.: Shim. S. C. J. Photochem. Photobiol A 1997.107, 137

9. Shin. E. J.: Lee, S. H. Bull. Konan Chem. Soc. 2002. 23.1309.

10. Shin. E. J.: Choi, S. W. J. Photochem. Photobiol A 1998. 114. 23.

11. Shit1. E. T. Bull. Korem Chent. Soc. 1999. 20. 1263.

12. Shin. E. T.: Stackow. R.: Foote. C. S. Phns Chem. Chem. Phns 2002. +5088

13. Shin. E. J. Bull. Korean Chem. Soc. 2002. 23, 1685. 